\title{
Lung function, pharmacokinetics, and tolerability of inhaled indacaterol maleate and acetate in asthma patients
}

David Miller ${ }^{1}$, Soniya Vaidya ${ }^{2 * *}$, Juergen Jauernig ${ }^{3}$, Brian Ethell ${ }^{4}$, Kristina Wagner ${ }^{4}$, Rajkumar Radhakrishnan ${ }^{5}$ and Hanns-Christian Tillmann ${ }^{6^{*}}$

\begin{abstract}
Background: Indacaterol maleate delivered with the Breezhaler ${ }^{\circledast}$ inhalation device is a long-acting $\beta_{2}$-agonist approved for chronic obstructive pulmonary disease. In the development of a once daily, inhaled fixed dose combination (FDC) of indacaterol, glycopyrronium bromide (a long-acting muscarinic antagonist), and mometasone furoate (an inhaled corticosteroid [ICS]) for the treatment of patients with asthma, the acetate salt of indacaterol is used instead of the maleate salt. Here, we investigated the lung function, pharmacokinetics (PK) and safety of indacaterol maleate $150 \mu \mathrm{g}$ once daily (o.d.) and indacaterol acetate $150 \mu \mathrm{g}$ o.d. in comparison with placebo.

Methods: This was a randomised, double-blind, three-period crossover study (ClinicalTrials.gov identifier, NCT03257995) in patients with asthma on background ICS therapy. Patients with percent predicted prebronchodilator forced expiratory volume per second $\left(\mathrm{FEV}_{1}\right) \geq 50 \%$ and $\leq 90 \%$ were included in the study. Patients received indacaterol maleate $150 \mu$ g o.d., indacaterol acetate $150 \mu \mathrm{g}$ o.d., or placebo on top of stable background ICS in randomised sequence. Trough FEV 1 was assessed after 14 days of treatment. PK of indacaterol salts were assessed at steady state after 14 days of treatment; peak expiratory flow (PEF) rate and rescue medication use were collected with a combined PEF-meter/electronic diary throughout the study.
\end{abstract}

Results: Of the 54 adult patients (median age of 48 years), 51 patients completed the study. Both indacaterol salts demonstrated statistically significant improvements in trough $\mathrm{FEV}_{1}$ of $186 \mathrm{~mL}$ (maleate) and $146 \mathrm{~mL}$ (acetate) compared with placebo (both $P<0.001$ ). $\mathrm{FEV}_{1} \mathrm{AUC}_{0-4 h}$ improved by $248 \mathrm{~mL}$ (maleate) and $245 \mathrm{~mL}$ (acetate), and PEF by $33 \mathrm{~L} / \mathrm{min}$ (maleate) and $30.8 \mathrm{~L} / \mathrm{min}$ (acetate) versus placebo. Systemic exposure of indacaterol $\left(A \cup C_{0-24 h, s s}\right.$ and $C_{\text {max,ss }}$ on Day 14) was comparable after administration of both salt forms. Both salt forms demonstrated a good safety profile and were well tolerated, with a difference in the reporting frequency of AEs of coughing (maleate, 23.5\%; acetate, 0\%).

Conclusions: In patients with asthma, indacaterol maleate and acetate elicited comparable and significant improvements in lung function compared with placebo and achieved comparable systemic exposure. Both indacaterol salts were safe and well tolerated.

Trial registration: ClinicalTrials.gov NCT03257995 June 06, 2017

Keywords: Asthma, Pharmacokinetic, Pharmacodynamics, Efficacy, LABA, Randomised control trial

\footnotetext{
* Correspondence: hanns-christian.tillmann@novartis.com

**Soniya Vaidya was an employee of Novartis Institutes for Biomedical

Research, Cambridge, MA, United States during the conduct of the study.

${ }^{6}$ Novartis Institutes for Biomedical Research, Basel, Switzerland

Full list of author information is available at the end of the article
}

(c) The Author(s). 2020 Open Access This article is licensed under a Creative Commons Attribution 4.0 International License, which permits use, sharing, adaptation, distribution and reproduction in any medium or format, as long as you give appropriate credit to the original author(s) and the source, provide a link to the Creative Commons licence, and indicate if changes were made. The images or other third party material in this article are included in the article's Creative Commons licence, unless indicated otherwise in a credit line to the material. If material is not included in the article's Creative Commons licence and your intended use is not permitted by statutory regulation or exceeds the permitted use, you will need to obtain permission directly from the copyright holder. To view a copy of this licence, visit http://creativecommons.org/licenses/by/4.0/. The Creative Commons Public Domain Dedication waiver (http://creativecommons.org/publicdomain/zero/1.0/) applies to the data made available in this article, unless otherwise stated in a credit line to the data. 


\section{Introduction}

Asthma is a chronic inflammatory disorder of the airways, associated with airway hyper-responsiveness that leads to recurrent episodes of wheezing, breathlessness, chest tightness, and coughing [1, 2]. The focus of asthma management strategies is symptom control, lung function improvement, and reduction in the risk of asthmarelated exacerbations [1].

In patients with persistent symptoms and exacerbations, the Global Initiative for Asthma (GINA) 2019 report recommends the use of high-dose inhaled corticosteroids (ICS) and/or ICS plus long-acting $\beta_{2}$-agonists (ICS/LABA) [1]. In patients who remain uncontrolled on medium- or high-dose ICS/LABA, add-on treatment with long-acting muscarinic antagonist (LAMA), tiotropium, is a proposed treatment option [1].

Indacaterol maleate was the first LABA approved for use in the EU (2009) as a once-daily (o.d.) maintenance monotherapy in patients with chronic obstructive pulmonary disease (COPD) as $\mathrm{Onbrez}^{\bullet}$ Breezhaler $^{\circledR}$ [3]. In 2013, the combination therapy of indacaterol maleate and the LAMA glycopyrronium was approved in the EU and Japan as an once-daily dual bronchodilator therapy in COPD (Ultibro ${ }^{\circ}$ Breezhaler $^{\bullet}[4,5]$ ). Indacaterol maleate shows a rapid onset of action within minutes of administration and provides $24 \mathrm{~h}$ bronchodilation in patients with COPD [6]. Since its approval, the efficacy and safety of indacaterol in patients with COPD has been established through numerous randomised controlled trials and real-world evidence studies [6-9].

The INVOLVE study which involved COPD patients, which assessed the long-term (52-week) efficacy and safety of indacaterol maleate $(150 \mu$ g o.d., delivered with the Breezhaler ${ }^{\oplus}$ device) showed a significant improvement in trough forced expiratory volume in $1 \mathrm{~s}\left(\mathrm{FEV}_{1}\right)$ over formoterol $(12 \mu \mathrm{g}$ twice daily [b.i.d.]) [7, 10]. Several studies have demonstrated that indacaterol maleate is highly potent and has a good safety profile in patients with asthma and COPD [11-15].

In Phase III clinical studies of indacaterol maleate in COPD patients, healthcare providers observed during clinic visits that some patients experienced a sporadic cough that occurred usually within $15 \mathrm{~s}$ following inhalation and typically lasted for $5 \mathrm{~s}$ (about $10 \mathrm{~s}$ in current smokers). Indacaterol acetate was considered to potentially elicit less coughing [16]. Indacaterol acetate, an alternative salt form of indacaterol maleate, has been developed as part of two different once-daily inhaled fixed dose combinations for treatment of asthma. The first combination comprises of indacaterol acetate and mometasone furoate (LABA/ICS), and another combination contains indacaterol acetate, glycopyrronium bromide and mometasone furoate (LABA/LAMA/ICS) $[10,17]$.

Findings from an experimentally informed biophysical modelling of the pulmonary drug delivery process supported the formulation and process development of indacaterol acetate batches for clinical development [18].

The aim of this clinical salt-bridging study was to compare the lung function, pharmacokinetics (PK), and safety of indacaterol maleate $150 \mu \mathrm{g}$ o.d. and indacaterol acetate $150 \mu$ g o.d. versus placebo in patients with asthma.

\section{Methods}

\section{Study design}

This was a double-blind, placebo-controlled, threeperiod complete block, cross-over, US-based multicenter Phase II study in patients with asthma (ClinicalTrials.gov identifier, NCT03257995).

The study was conducted between September 5, 2017 and January 18, 2018 and included a 14-day screening period to assess the eligibility of patients. The study comprised three treatment periods with a washout period of 7-14 days in between. Patients were randomised $(1: 1: 1: 1: 1: 1)$ to one of six treatment sequences across three different treatment periods (14 days each) to receive indacaterol maleate $(150 \mu \mathrm{g}$ o.d.), indacaterol acetate $(150 \mu \mathrm{g}$ o.d.) or placebo (Fig. 1). All treatments were delivered using the Breezhaler ${ }^{\circledR}$ inhaler. Patients were provided with an inhaled short-acting $\beta_{2}$-agonist (SABA; $100 \mu \mathrm{g} /$ puff salbutamol or other SABA) at matching dose-strength as rescue medication throughout the study and remained on background ICS at the dose strength taken during screening.

\section{Patients}

Male and female patients (aged $\geq 18$ years) with asthma (physician documented) for $>1$ year, receiving a stable dose of ICS for $\geq 4$ weeks prior to screening were included in the study if they had a pre-bronchodilator $\mathrm{FEV}_{1} \geq 50 \%$ and $\leq$ $90 \%$ of the predicted normal value at screening, and demonstrated an increase in $\mathrm{FEV}_{1}$ of $\geq 12 \%$ and $\geq 200 \mathrm{~mL}$ within $30 \mathrm{~min}$ after administration of $400 \mu \mathrm{g}$ salbutamol $/ 360 \mu \mathrm{g}$ albuterol (or equivalent dose) at screening. Patients were excluded from the study if they had experienced an asthma attack/exacerbation requiring systemic corticosteroids or hospitalisation or emergency room visit 6 weeks prior to screening, were current smokers (patients who have smoked or inhaled tobacco products 6 months prior to screening, or who have a smoking history of greater than 10 pack years), had previous intubation for a severe asthma attack/exacerbation, required the use of $\geq 12 \mathrm{puffs} / 24 \mathrm{~h}$ of rescue medication for $48 \mathrm{~h}$ (over 2 consecutive days) during screening prior to randomisation (list of key inclusion and exclusion criteria is provided in the supplementary material).

\section{Objectives and assessments Lung function}

The primary objective of the study was to assess the bronchodilator effect of indacaterol acetate and 


\begin{tabular}{|c|c|c|c|c|}
\hline Screening & Randomisation | & \multicolumn{3}{|c|}{ Three treatment-period comprising of 14 Days each } \\
\hline $\begin{array}{l}-14 \text { to }-1 \\
\text { Days }\end{array}$ & Day $1^{*}$ & $\begin{array}{l}\text { Treatment period } 1 \text { with } \\
\text { overnight stay; } \\
\text { Day } 14 \text { to } 15\end{array}$ & $\begin{array}{l}\text { Treatment period } 2 \text { with } \\
\text { overnight stay; } \\
\text { Day } 14 \text { to } 15\end{array}$ & $\begin{array}{l}\text { Treatment period } 3 \text { with } \\
\text { overnight stay; Day } 14 \text { to } 15 \\
\text { (end of study visit) }\end{array}$ \\
\hline \multicolumn{3}{|c|}{$\rightarrow$ Spirometry for eligibility } & Spirometry for treatment effect & $\rightarrow$ Spirometry for treatment effect \\
\hline $\begin{array}{l}\text { Sequence } 1 \\
n=9\end{array}$ & & $\begin{array}{c}\text { Indacaterol maleate } \\
150 \mu \mathrm{g} \text { o.d. }\end{array}$ & $\begin{array}{l}\text { Indacaterol acetate } \\
150 \mu \mathrm{g} \mathrm{o.d.}\end{array}$ & Placebo \\
\hline $\begin{array}{l}\text { Sequence } 2 \\
n=9\end{array}$ & & $\begin{array}{l}\text { Indacaterol acetate } \\
150 \mu \mathrm{g} \text { o.d. }\end{array}$ & Placebo & $\begin{array}{l}\text { Indacaterol maleate } \\
150 \mu \mathrm{g} \text { o.d. }\end{array}$ \\
\hline $\begin{array}{c}\text { Sequence } 3 \\
n=9\end{array}$ & & Placebo & $\begin{array}{c}\text { Indacaterol maleate } \\
150 \mu \mathrm{g} \text { o.d. }\end{array}$ & $\begin{array}{c}\text { Indacaterol acetate } \\
150 \mu \mathrm{\mu g} \text { o.d. }\end{array}$ \\
\hline $\begin{array}{l}\text { Sequence } 4 \\
\quad n=9\end{array}$ & & $\begin{array}{c}\text { Indacaterol maleate } \\
150 \mu \mathrm{g} \text { o.d. }\end{array}$ & Placebo & $\begin{array}{c}\text { Indacaterol acetate } \\
150 \mu \mathrm{g} \mathrm{o.d} \text {. }\end{array}$ \\
\hline $\begin{array}{l}\text { Sequence } 5 \\
\quad \mathrm{n}=9\end{array}$ & & $\begin{array}{c}\text { Indacaterol acetate } \\
150 \mu \mathrm{g} \text { o.d. }\end{array}$ & $\begin{array}{c}\text { Indacaterol maleate } \\
150 \mu \mathrm{g} \text { o.d. }\end{array}$ & Placebo \\
\hline $\begin{array}{l}\text { Sequence } 6 \\
\quad n=9\end{array}$ & & Placebo & $\begin{array}{c}\text { Indacaterol acetate } \\
150 \mu \mathrm{g} \mathrm{o.d.}\end{array}$ & $\begin{array}{c}\text { Indacaterol maleate } \\
150 \mu \mathrm{g} \text { o.d. }\end{array}$ \\
\hline \multicolumn{5}{|c|}{ Rescue medication } \\
\hline
\end{tabular}

indacaterol maleate salts compared with placebo in terms of trough $\mathrm{FEV}_{1}$ (mean of $\mathrm{FEV}_{1}$ at $23 \mathrm{~h} 15 \mathrm{~min}$ and $23 \mathrm{~h} 45 \mathrm{~min}$ ) after 14 days of treatment.

As secondary objectives, we evaluated the standardized $\mathrm{FEV}_{1}$ area under the curve from 0 to $4 \mathrm{~h}\left(\mathrm{FEV}_{1} \mathrm{AUC}_{0-}\right.$ $4 \mathrm{~h}$, as well as $\mathrm{FEV}_{1}$, forced vital capacity (FVC) and forced expiratory flow $\left(\mathrm{FEF}_{25-75 \%}\right)$ at each post-dose time point after 14 days of treatment. The spirometry measurements were performed during the following time points: $45 \mathrm{~min}$ and $-15 \mathrm{~min}, 5 \mathrm{~min}, 15 \mathrm{~min}, 30 \mathrm{~min}$, $1 \mathrm{~h}, 2 \mathrm{~h}, 4 \mathrm{~h}, 8 \mathrm{~h}, 12 \mathrm{~h}, 23 \mathrm{~h} 15 \mathrm{~min}, 23 \mathrm{~h} 45$ on Day 14. Peak expiratory flow (PEF) rate was assessed b.i.d., once in the morning and once in the evening $(\sim 12 \mathrm{~h}$ later $)$ throughout the study PEF measurements were taken using the peak flow meter device taken between Day 8 and 14 days of each treatment were pre-specified to be analysed as a secondary objective.

\section{Rescue medication}

The use of rescue medication was recorded throughout the entire study taken b.i.d. using the eDiary and compared between the indacaterol salts and placebo on Days 8 and 14 .

\section{Pharmacokinetic endpoints}

Steady-state PK, including area under the plasma concentration vs. time curve from 0 to $24 \mathrm{~h}\left(\mathrm{AUC}_{0-24 \mathrm{~h}, \mathrm{ss}}\right)$, maximum $\left(\mathrm{C}_{\mathrm{max}, \mathrm{ss}}\right)$, minimum $\left(\mathrm{C}_{\mathrm{min}, \mathrm{ss}}\right)$, and average $\left(\mathrm{C}_{\mathrm{avg}, \mathrm{ss}}\right)$ plasma concentration and time to reach maximal concentrations $\left(\mathrm{T}_{\mathrm{max}, \mathrm{ss}}\right)$ were also assessed as secondary objectives.

\section{Safety}

Safety assessments included monitoring of all adverse events (AEs) and serious adverse events (SAEs), evaluating their severity and relationship to treatment.

\section{Pharmacokinetic analysis}

Blood samples for PK analysis on Day 14 in each period were collected at pre-dose, $0.08,0.16,0.25,0.50,1,2,4,8$, 12 and $24 \mathrm{~h}$ post-dose. All blood samples were taken by either direct venipuncture or an indwelling catheter inserted in a forearm vein. At specified time points, $2 \mathrm{~mL}$ blood sample was collected in lithium heparin tubes. Within $15 \mathrm{~min}$, the sample was centrifuged at $4{ }^{\circ} \mathrm{C}$ for $15 \mathrm{~min}$ at approximately $1500 \mathrm{~g}$. All plasma samples were frozen within 30 min of collection and stored at $-20^{\circ} \mathrm{C}$ or colder, pending analyses. Samples corresponding to treatment periods where patients received placebo were not analysed. The concentrations of indacaterol in plasma were determined by a validated liquid chromatography-mass spectrometry/ mass spectrometry (LC-MS/MS) method [19]; the Lower Limit of Quantification (LLOQ) was $5.00 \mathrm{pg} / \mathrm{mL}$. Concentrations were expressed in $\mathrm{pg} / \mathrm{mL}$ units and referred to the free base of indacaterol. Concentrations below the LLOQ were treated as zero in summary statistics of concentration data as well as PK parameter calculations. PK parameters $\left(\mathrm{AUC}_{0-24 \mathrm{~h}, \mathrm{ss}}, \mathrm{C}_{\mathrm{max}, \mathrm{ss}}, \mathrm{T}_{\mathrm{max}, \mathrm{ss}}\right)$ were determined using WinNonlin Phoenix (version 6.4; Certara, Princeton, NJ, USA).

\section{Statistical analysis}

The PK/PD analysis sets included all patients who received any study drug and experienced no major 
protocol deviations with relevant impact on PK/PD data. Sample size calculations were based on the primary endpoint of trough $\mathrm{FEV}_{1}$, assuming within-patient standard deviation (SD) of $230 \mathrm{~mL}$ (derived from an earlier study, data on file) and with 42 patients completing the study, the power to detect a significant difference between indacaterol salts and placebo at the 2-sided 5\% alpha level, assuming a true difference of at least $170 \mathrm{~mL}$ in trough $\mathrm{FEV}_{1}$, would be at least $90 \%$. The primary endpoint, trough $\mathrm{FEV}_{1}$, after 14 days of treatment was analysed using Analysis Of Variance (ANOVA) with treatment, period and sequence as fixed effects and subject within sequence as a random effect.

Standardised $\mathrm{FEV}_{1} \mathrm{AUC}_{0-4 \mathrm{~h}}$ between baseline (pre-dose) and $4 \mathrm{~h}$ post-dose on Day 14 was analysed using the same ANOVA model as for the primary. The remaining secondary spirometry parameters were analysed using repeated measures analysis of variance (ANOVA) model, with treatment, period, and sequence as fixed effects and subject nested within sequence was included as random effect. Time was repeated within each subject by period interaction term. An unstructured variance-covariance matrix was considered for the repeated measures residuals. The adjusted mean difference between indacaterol salts and placebo and their corresponding two-sided 95\% confidence intervals (CIs) along with $P$ values for the differences were reported. The log-transformed PK parameters $\mathrm{AUC}_{0-24 \mathrm{~h}, \mathrm{ss}}$ and $\mathrm{C}_{\mathrm{max}, \mathrm{ss}}$ on Day 14 were compared for indacaterol acetate (test) relative to indacaterol maleate (reference) using a mixed-effects model with sequence, treatment, and period as fixed effects and patient nested within sequence as random effect. $T_{\text {max,ss }}$ was analysed using non-parametric methods. The median difference and the $90 \% \mathrm{CI}$ of the median difference in $\mathrm{T}_{\mathrm{max}, \mathrm{ss}}$ was estimated using Hodges-Lehmann estimation procedure. Averaged morning and evening puffs and overall number of puffs of rescue medications and averaged morning and evening and overall number of PEF measurements were also analysed using ANOVA similar to trough $\mathrm{FEV}_{1}$.

The safety summaries included all patients who received any treatment (indacaterol salts and/or placebo). AEs by system organ class (SOC) and preferred term (PT), and AEs leading to permanent discontinuation of study drug by SOC and PT with a breakdown by treatment subject with multiple AEs within a body system and treatment period, were only counted once toward the total of the body system and treatment.

\section{Results}

\section{Patients}

In total, 54 patients were randomised, with nine patients in each treatment sequence. Of these, 51 completed the study. Three patients discontinued the study; one due to $\mathrm{AE}$ (upper respiratory tract infection and asthma exacerbation) and two discontinued due to deviations from study protocol (administration of prohibited concomitant medication). The median age of the patients in the study was 48 years (range: 26-70). Most patients were female (66.7\%). The population mean \pm SD body mass index was $29.9 \pm 5.1 \mathrm{~kg} /$ $\mathrm{m}^{2}$ (Table 1). Patients had mean pre-bronchodilator FEV of $2.229 \mathrm{~L}$ and mean post-bronchodilator $\mathrm{FEV}_{1}$ of $2.693 \mathrm{~L}$ with an average reversibility of $21 \%$ at baseline.

\section{Lung function}

After 14 days of treatment, both indacaterol maleate $(N=47)$ and indacaterol acetate $(N=49)$ showed a statistically significant improvement in trough $\mathrm{FEV}_{1}$ compared with placebo (both $P<0.001$ ).

The LS mean treatment differences versus placebo in trough $\mathrm{FEV}_{1}$ with indacaterol maleate was $186 \mathrm{~mL}(95 \% \mathrm{CI}$, 129 to $243 \mathrm{~mL}$ ) and with indacaterol acetate was $146 \mathrm{~mL}$ (95\% CI, 90 to $203 \mathrm{~mL})(P<0.001$ for both comparisons; Fig. 2).

After 14 days of treatment the LS mean treatment differences versus placebo in $\mathrm{FEV}_{1} \mathrm{AUC}_{0-4 \mathrm{~h}}$ with indacaterol maleate $(N=51)$ was $248 \mathrm{~mL}$, and $245 \mathrm{~mL}$ with indacaterol acetate $(N=52 ; P<0.001$ for both comparisons; Fig. 3$)$.

Indacaterol maleate and indacaterol acetate showed substantial improvements in the mean pre-dose morning, evening, and overall PEF compared with placebo

Table 1 Demographic and clinical characteristics at baseline

\begin{tabular}{|c|c|}
\hline Parameters & Total $(N=54)$ \\
\hline Age, years, median (range) & $48(26-70)$ \\
\hline \multicolumn{2}{|l|}{ Sex, n (\%) } \\
\hline Men & $18(33.3)$ \\
\hline Women & $36(66.7)$ \\
\hline Body mass index $\left(\mathrm{kg} / \mathrm{m}^{2}\right)$ & $29.9 \pm 5.1$ \\
\hline \multirow[t]{2}{*}{ Race, n (\%) } & Black 7 (13.0) \\
\hline & White 47 (87.0) \\
\hline \multirow[t]{4}{*}{ Ethnicity, n (\%) } & Hispanic or Latino 8 (14.8) \\
\hline & Not Reported 30 (55.6) \\
\hline & Unknown 8 (14.8) \\
\hline & Other 8 (14.8) \\
\hline Pre-bronchodilator $\mathrm{FEV}_{1}, \mathrm{~L}$ & $2.229 \pm 0.679$ \\
\hline Post-bronchodilator FEV $1, \mathrm{~L}$ & $2.693 \pm 0.816$ \\
\hline Pre-bronchodilator $\mathrm{FEV}_{1}, \%$ predicted & $71 \pm 11$ \\
\hline Post-bronchodilator $\mathrm{FEV}_{1}, \%$ predicted & $86 \pm 12$ \\
\hline $\mathrm{FEV}_{1}$ Reversibility ${ }^{\mathrm{a}}, \mathrm{L}$ & $0.464 \pm 0.241$ \\
\hline $\mathrm{FEV}_{1}$ Reversibility ${ }^{\mathrm{b}}(\%)$ & $21 \pm 10$ \\
\hline
\end{tabular}

Data are represented as mean \pm SD unless otherwise specified

FEV 1 Forced expiratory volume in $1 \mathrm{~s}$, SD Standard deviation

${ }^{a}$ Reversibility (L) is calculated as: $\mathrm{FEV}_{1}$ (post-bronchodilator) $\mathrm{FEV}_{1}$ (pre-bronchodilator)

${ }^{\mathrm{b}}$ Reversibility (\%) is calculated as: (FEV ${ }_{1}$ (post-bronchodilator) - $\mathrm{FEV}_{1}$ (prebronchodilator) $\times 100) / \mathrm{FEV}_{1}$ (prebronchodilator) 


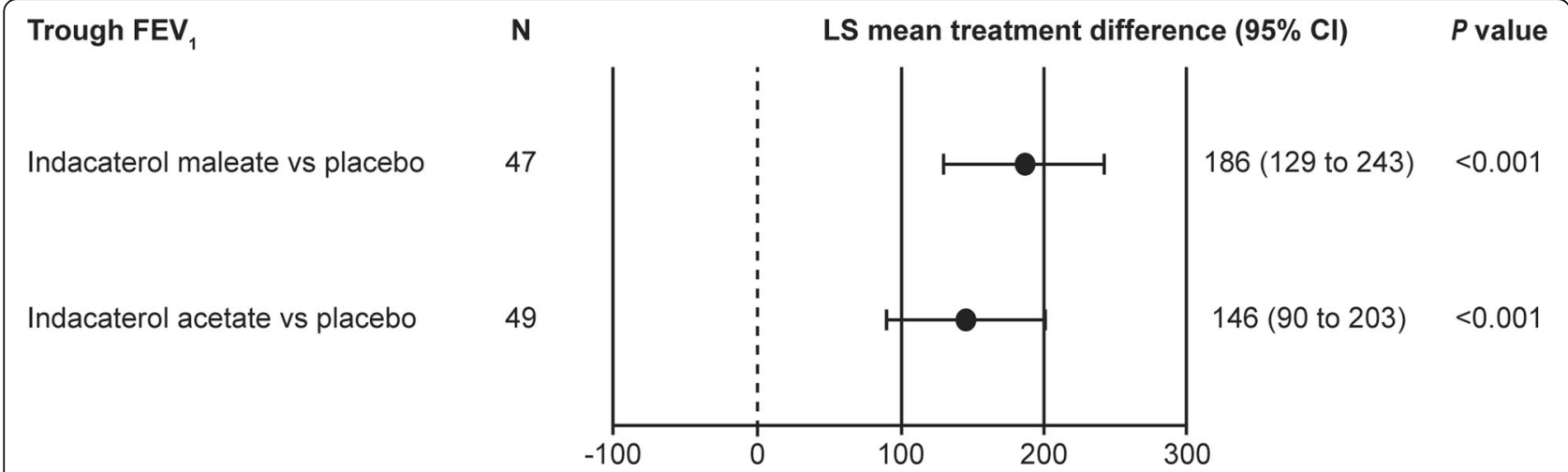

Fig. 2 Significant improvement in trough $\mathrm{FEV}_{1}(\mathrm{~mL})$ with indacaterol maleate and indacaterol acetate versus placebo at Day 14. Data presented as LS mean treatment differences $(95 \% \mathrm{Cl})$. Cl, confidence interval; $\mathrm{FEV}_{1}$, forced expiratory volume in $1 \mathrm{~s}$; LS, least square; $\mathrm{N}$, number of patients

over Days $8-14$ of each respective treatment period. The mean treatment difference in morning PEF compared with placebo was $30.9 \mathrm{~L} / \mathrm{min}$ and $29.6 \mathrm{~L} / \mathrm{min}$ for indacaterol maleate $(N=51)$ and indacaterol acetate $(N=52)$, respectively, and the mean treatment difference in evening PEF compared with placebo was $34.8 \mathrm{~L} / \mathrm{min}$ and $32.7 \mathrm{~L} /$ min for indacaterol maleate and indacaterol acetate respectively. Improvements were observed in overall PEF for both the indacaterol salts compared with placebo (overall PEF; Fig. 4). Both indacaterol salts (maleate and acetate) showed comparable and statistically significant improvements in other assessed lung function parameters at all assessed time points compared with placebo $\left(\mathrm{FEV}_{1}\right.$ : Table S1, FVC: Table S2, $\mathrm{FEF}_{25-75 \%}$ : Table S3).

\section{Rescue medication}

The LS mean for rescue medication use between Days 8-14 of each treatment period was 1.01 puffs/day each for both the indacaterol salts (maleate, $N=51$; acetate, $N=52)$ and 1.43 puffs/day for placebo $(N=51)$. A reduction of 0.42 in LS mean puffs/day was observed with both indacaterol salts compared with placebo (maleate, $P=0.009$; acetate, $P=0.008)$.

\section{Systemic pharmacokinetics}

Indacaterol maleate and indacaterol acetate showed similar systemic plasma concentration-time profiles on Day 14 (Fig. 5). Both indacaterol salts showed rapid absorption with peak concentrations achieved within 30 min post-inhalation.

There was no relevant difference in exposure $\left(\mathrm{AUC}_{0-}\right.$ 24h,ss and $C_{\text {max,ss }}$ ) at steady state between indacaterol acetate and indacaterol maleate (Table 2). The median time to reach peak concentration $\left(\mathrm{T}_{\max }\right)$ post-dose was $15 \mathrm{~min}$ with indacaterol maleate and $28 \mathrm{~min}$ with indacaterol acetate.

Geometric mean ratios (indacaterol acetate vs. indacaterol maleate) and the corresponding 90\% CIs for both $\mathrm{AUC}_{0-24 \mathrm{~h}, \mathrm{ss}}$ and $\mathrm{C}_{\text {max,ss }}$ were within the bioequivalence limits (90\% CI range: 0.80 to 1.25 ) [20], indicating a comparable exposure from both the indacaterol salts (Table 3).

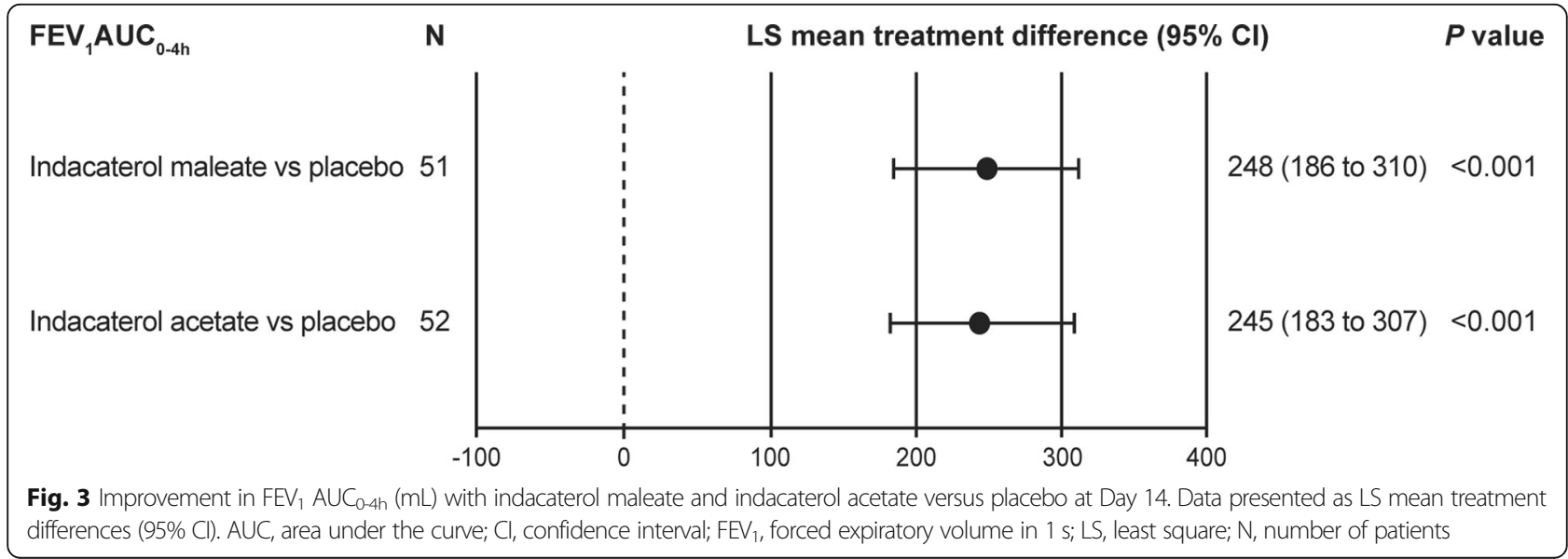




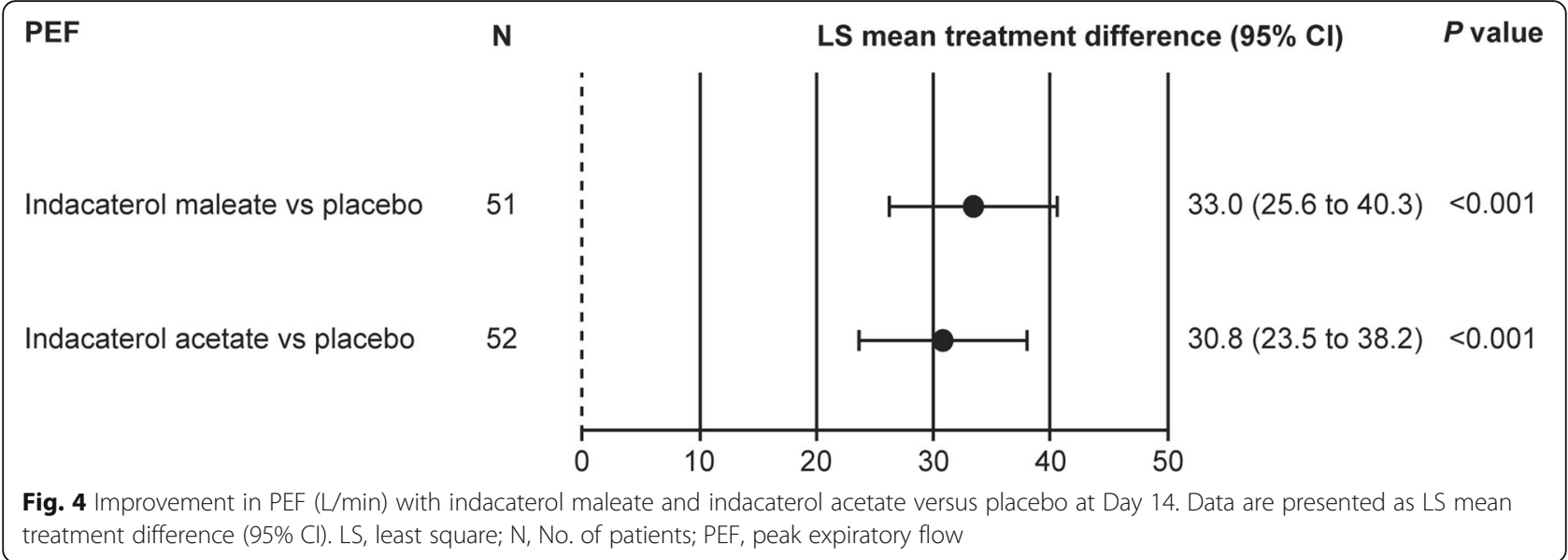

\section{Safety}

Safety data for all study treatments is shown in Table 4. The overall incidence of AEs was 27.5\% for indacaterol maleate, $13.5 \%$ for indacaterol acetate, and $17.0 \%$ for placebo. Indacaterol acetate was not associated with AEs of cough $(n=0)$, whereas 12 patients $(23.5 \%)$ reported cough with indacaterol maleate. Four severe AEs were reported in two patients after they received indacaterol acetate $150 \mu \mathrm{g}(3.8 \%, n=2)$, one patient reported streptococcal pharyngitis and sinusitis and the other patient reported upper respiratory tract infection and asthma exacerbation as severe AE. one severe AE (cholangitis) was reported in a patient treated with placebo $(1.9 \%, n=1)$. In total, two serious adverse events (SAEs), pharyngitis streptococcal and sinusitis were reported in one patient during the indacaterol acetate treatment period. This patient discontinued from the study; overall, none of the severe AEs or
SAEs were considered to be related to the study treatments by the investigator.

\section{Discussion}

The findings from this Phase II salt-bridging study demonstrate the efficacy and safety of indacaterol maleate and indacaterol acetate in patients with asthma. It also provides evidence of similar systemic exposure to indacaterol following administration of either of its salt forms.

The primary objective was met with both indacaterol salts (maleate and acetate) demonstrating statistically significant $(P<0.001)$ and clinically meaningful improvements in mean trough $\mathrm{FEV}_{1}$ compared with placebo $(186 \mathrm{~mL}$ and $146 \mathrm{~mL}$, respectively) following the 14-day treatment period on top of stable ICS background therapy. These improvements are within the range reported in studies that investigated other LABAs such as formoterol

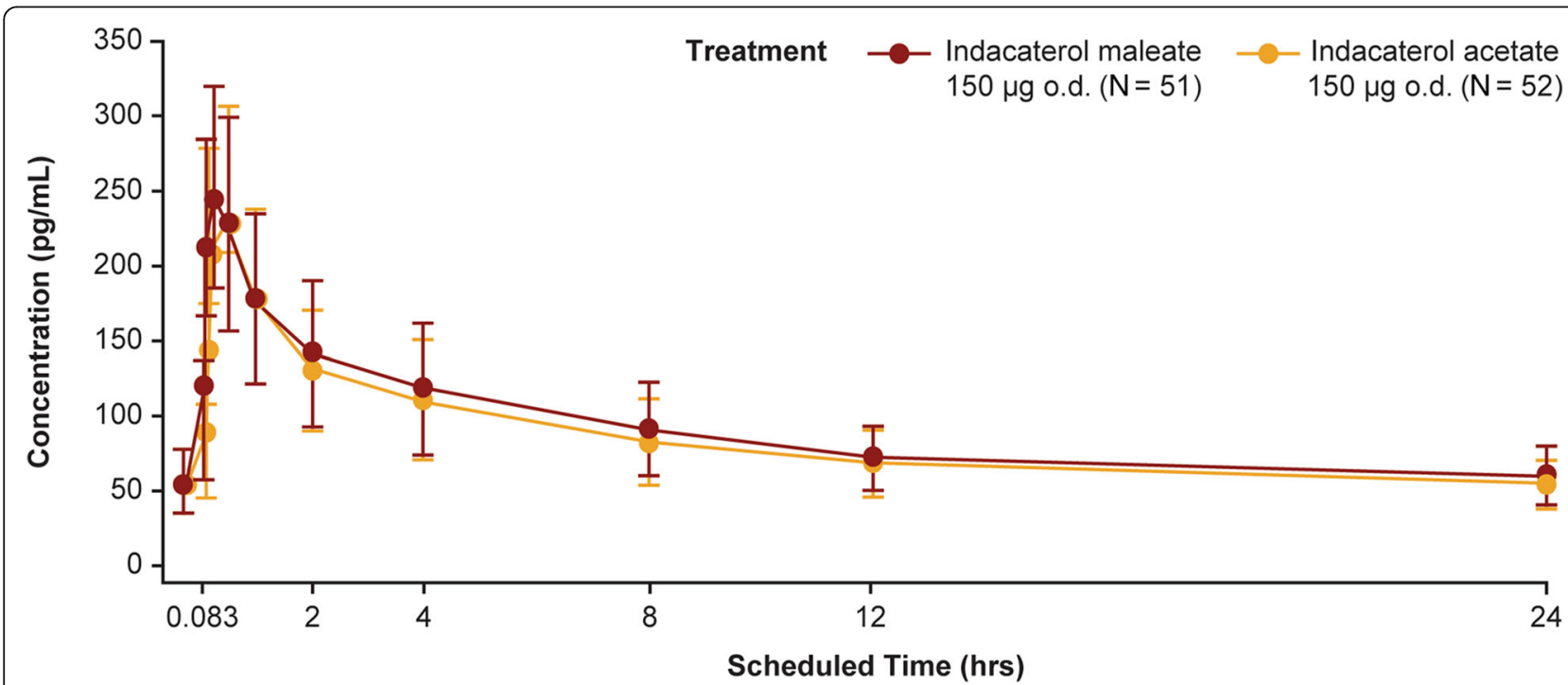

Fig. 5 Plasma concentration-time profiles for indacaterol maleate and indacaterol acetate on Day 14. Data presented as arithmetic mean \pm SD; error bars indicate SD values; o.d., once daily 
Table 2 Summary statistics of plasma PK parameters for indacaterol salts on Day 14

\begin{tabular}{|c|c|c|}
\hline & $\begin{array}{l}\text { Indacaterol maleate } \\
150 \mu \mathrm{g} \text { o.d. } \\
(N=51)\end{array}$ & $\begin{array}{l}\text { Indacaterol acetate } \\
150 \mu \mathrm{g} \text { o.d. } \\
(N=52)\end{array}$ \\
\hline$A \cup C_{0-24 h, s s,} h^{*} p g / m L$ & $2300 \pm 732(31.8)$ & $2050 \pm 636(31.0)$ \\
\hline$C_{\max , 5 s,} \mathrm{pg} / \mathrm{mL}$ & $264 \pm 80.2(30.3)$ & $236 \pm 74.0(31.3)$ \\
\hline $\mathrm{T}_{\max , s 5,} \mathrm{~h}$ & 0.250 (0.18 to 0.85$)$ & 0.467 (0.18 to 1.00$)$ \\
\hline$C_{\text {min,ss }}(\mathrm{pg} / \mathrm{mL})$ & $56.4 \pm 21.7(38.4)$ & $52.6 \pm 18.1$ (34.4) \\
\hline$C_{a v, s s}(p g / m L)$ & $94.1 \pm 31.3(33.3)$ & $85.5 \pm 26.5(31.0)$ \\
\hline
\end{tabular}

All values are represented as mean $\pm S D(C V \%)$, except for $T_{\max , s s}$ which is presented as median (range)

AUC Area under the curve, $C_{a v}$ Average plasma concentration, $C_{\max }$ Maximum plasma concentration, $C_{\min }$ Minimum plasma concentration, $C V$ Coefficient of variation, o.d. Once daily, PK Pharmacokinetics, SD Standard deviation, $T_{\max }$ Time to reach maximal concentrations

and salmeterol b.i.d. in patients with asthma [21-24], although these studies assessed change in $\mathrm{FEV}_{1}$ at different time points from the present study.

Donohue et al. observed that indacaterol o.d. showed similar improvements in trough $\mathrm{FEV}_{1}$ at Day 14 and Day 84 [25]. Improvements in lung function were also observed in secondary endpoints including $\mathrm{FEV}_{1}, \mathrm{AUC}_{0-4 \mathrm{~h}}$, PEF, and FVC. These findings support the substantial bronchodilator effect of indacaterol and subsequent improvement in airflow limitation, which is one of the key goals for patients with asthma [1].

Upon comparison of indacaterol acetate vs. indacaterol maleate, the geometric mean ratio $(90 \% \mathrm{CI})$ for $\mathrm{AUC}_{0-24 \mathrm{~h}, \mathrm{ss}}$ was 0.897 (90\% CI: $0.854,0.942)$ and for $\mathrm{C}_{\text {max,ss }}$ was 0.891 (90\% CI: 0.846, 0.939). Thus, the geometric mean ratio and 90\% CI for both $\mathrm{AUC}_{0-24 \mathrm{~h}, \mathrm{ss}}$ and $\mathrm{C}_{\max }$ fell well within the bioequivalence limits ( $90 \%$ CI: 0.80 to 1.25 ) [20], indicating similar exposure from both salts. The PK parameters $\left(\mathrm{AUC}_{0-24 \mathrm{~h}, \mathrm{ss}}, \mathrm{C}_{\mathrm{max}, \mathrm{ss}}\right.$ and $\mathrm{T}_{\text {max,ss}}$ ) observed for indacaterol in this study were comparable to those reported previously following administration of $150 \mu \mathrm{g}$ indacaterol acetate or indacaterol maleate at steady state in healthy volunteers $[26,27]$.

Although formulation bridging studies are typically conducted as single dose crossover studies in healthy volunteers, the use of a multiple dose crossover study

Table 3 Comparative analysis of PK between indacaterol maleate and acetate on Day 14

\begin{tabular}{|c|c|c|c|}
\hline & $\begin{array}{l}\text { Indacaterol } \\
\text { maleate } \\
150 \mu \text { g o.d. } \\
(N=51)\end{array}$ & $\begin{array}{l}\text { Indacaterol } \\
\text { acetate } \\
150 \mu \text { g o.d. } \\
(N=52)\end{array}$ & $\begin{array}{l}\text { Indacaterol acetate } \\
\text { versus Indacaterol } \\
\text { maleate }\end{array}$ \\
\hline \multicolumn{4}{|c|}{ Geometric LSM ratio $(90 \% \mathrm{CI})$} \\
\hline $\begin{array}{l}A \cup C_{0-24 h, s s,} \\
h^{*} p g / m L\end{array}$ & $\begin{array}{l}2180 \text { (2020 to } \\
2350)\end{array}$ & $\begin{array}{l}1950(1820 \text { to } \\
2100)\end{array}$ & $\begin{array}{l}0.897 \text { ( } 0.854 \text { to } \\
0.942)\end{array}$ \\
\hline$C_{\text {max,ss! }} \mathrm{pg} / \mathrm{mL}$ & $\begin{array}{l}253 \text { (236 to } \\
273)\end{array}$ & $\begin{array}{l}226 \text { (210 to } \\
243)\end{array}$ & $\begin{array}{l}0.891 \text { ( } 0.846 \text { to } \\
0.939)\end{array}$ \\
\hline
\end{tabular}

AUC Area under the curve, $C_{\max }$ Maximum plasma concentration, $L S M$ Least square mean, o.d. Once daily, PK Pharmacokinetics design in asthma patients in the present study allowed evaluation of both PK and PD parameters for both salt forms in the intended indication at steady state.

Systemic PK following inhaled administration depends on a number of unique factors including the delivered dose (dose ex-mouth piece), fine particle mass or the respirable fraction of an inhaled dose, performance of the inhalation device and the ability of subjects to correctly use the inhalation device. Use of an experimentally informed biophysical modeling of the pulmonary drug delivery process to support the formulation and process development of indacaterol acetate batches for clinical development was a critical factor that enabled a successful bridging program for the indacaterol salts.

In the present study, patients treated with indacaterol maleate and indacaterol acetate demonstrated considerable reduction in the use of rescue medication compared with placebo. These improvements support the therapeutic benefit of indacaterol in controlling asthma symptoms. In addition, lowered use of rescue medication with indacaterol may help to alleviate side effects like cataract, diabetes, peptic ulcers, cardiovascular disease (CVD), cerebrovascular events and osteoporosis that are generally associated with the frequent and long term use of reliever medications [28-30].

Overall, the safety profile of both indacaterol salt forms was comparable with placebo and consistent with the established safety profile for inhaled indacaterol [31, 32]. The only notable difference was that indacaterol acetate was not associated with AEs of coughing in any of the patients, whereas it was observed in 12 patients in the indacaterol maleate treatment arm and in one patient in the placebo arm. No new safety signals were observed compared to those seen in previous studies with indacaterol [24, 31, 33]. The two SAEs of streptococcal pharyngitis and sinusitis were not suspected to be related to the study drug by the investigator.

A washout period of 7-14 days eliminated any potential carryover effect from the previous treatment period. Within-patient variability in $\mathrm{FEV}_{1}$ was predicted to be less than between-patient variability. Taking this into consideration, the crossover study design was chosen over a parallel-group design. The 14-day treatment period selected was sufficient to assess PK parameters at steady-state and to assess the effect of indacaterol treatment on lung function. It is supported by the observable change reported in previous studies [34, 35], which showed that indacaterol achieved PD steady-state within 14 days of once-daily administration in COPD patients $[34,35]$.

Indacaterol acetate was comparable to indacaterol maleate (both at a dose of $150 \mu \mathrm{g}$ o.d.) in terms of efficacy, systemic exposure and safety. These findings support the utility of indacaterol acetate as a LABA in two currently developed inhaled fixed dose combination 
Table 4 Incidence of treatment-emergent AEs by preferred term affecting $\geq 3 \%$ of total patients (safety analysis set)

\begin{tabular}{|c|c|c|c|c|}
\hline & $\begin{array}{l}\text { Indacaterol maleate } \\
150 \mu \mathrm{g} \text { o.d. } \\
n=51 \\
\mathrm{n}(\%)\end{array}$ & $\begin{array}{l}\text { Indacaterol acetate } \\
150 \mu \mathrm{g} \text { o.d. } \\
n=52 \\
\mathrm{n}(\%)\end{array}$ & $\begin{array}{l}\text { Placebo } \\
n=53 \\
\mathrm{n}(\%)\end{array}$ & $\begin{array}{l}\text { Total } \\
N=54 \\
\mathrm{n}(\%)\end{array}$ \\
\hline Number of patients with $\geq 1 \mathrm{AE}$ & $14(27.5)$ & $7(13.5)$ & $9(17.0)$ & $24(44.4)$ \\
\hline Cough & $12(23.5)$ & $0(0.0)$ & $1(1.9)$ & $13(24.1)$ \\
\hline Upper respiratory tract infection & $1(2.0)$ & $2(3.8)$ & $2(3.8)$ & $5(9.3)$ \\
\hline Arthralgia & $0(0.0)$ & $1(1.9)$ & $1(1.9)$ & $2(3.7)$ \\
\hline Sinusitis & $0(0.0)$ & $1(1.9)$ & $1(1.9)$ & $2(3.7)$ \\
\hline Vomiting & $1(2.0)$ & $1(1.9)$ & $0(0.0)$ & $2(3.7)$ \\
\hline
\end{tabular}

Data presented as $\mathrm{n}(\%)$

$A E$ Adverse event, o.d. Once daily

therapies for asthma: a once-daily LABA/ICS combination with mometasone furoate, and a once-daily LABA/ LAMA/ICS combination with glycopyrronium bromide and mometasone furoate.

\section{Conclusions}

In patients with asthma, both indacaterol maleate and indacaterol acetate achieved significant improvements in lung function compared with placebo and elicited similar systemic exposure. Both indacaterol salts were safe and overall well tolerated; no AEs of cough were observed with indacaterol acetate. These findings support indacaterol acetate as a potent LABA in inhaled combination therapies for patients with asthma.

\section{Supplementary information}

Supplementary information accompanies this paper at https://doi.org/10. 1186/s12931-020-01501-1.

Additional file 1.

\section{Abbreviations}

ANOVA: Analysis Of Variance; AEs: Adverse events; ECG: Electrocardiograms; FDC: Fixed dose combination; FEV 1 : Forced expiratory volume in $1 \mathrm{~s}$; FEV AUC: Forced expiratory volume in $1 \mathrm{~s}$ area under the curve; FVC: Forced vital capacity; ICS: Inhaled corticosteroid; LABA: Long-acting $\beta_{2}$-agonist; LABA/ ICS: Long-acting $\beta_{2}$-agonist/inhaled corticosteroid; LABA/LAMA/ICS: Longacting $\beta_{2}$-agonist/long-acting muscarinic antagonist/inhaled corticosteroids; LABA/LAMA: Long-acting $\beta_{2}$-agonist/long-acting muscarinic antagonist; LAMA: Long-acting muscarinic-antagonist; LC-MS/MS: Liquid chromatography-mass spectrometry/ mass spectrometry;

PK: Pharmacokinetics; PD: Pharmacodynamics; SAEs: Serious adverse events

\section{Acknowledgments}

The authors thank Aakash Katdare, Archana Jayaraman and Vatsal Vithlani of Novartis Healthcare Pvt. Ltd. for providing medical writing and editorial support in accordance with Good Publication Practice (GPP3) guidelines (http://www.ismpp.org/gpp3).

\section{Authors' contributions}

All authors have contributed substantially in data interpretation, development and revision of manuscript draft, and provided their consent and approval for publishing this manuscript.

\section{Funding}

The study was funded by Novartis Pharma AG, Basel, Switzerland.

\section{Availability of data and materials}

Novartis is committed to sharing with qualified external researchers, access to patient-level data and supporting clinical documents from eligible studies. These requests are reviewed and approved by an independent review panel on the basis of scientific merit. All data provided are anonymized to respect the privacy of patients who have participated in the trial in line with applicable laws and regulations.

\section{Ethics approval and consent to participate}

The study was conducted according to the ethical principles of the Declaration of Helsinki. Informed consent was obtained from all the study participants prior to initiation.

\section{Consent for publication}

Not applicable.

\section{Competing interests}

* Soniya Vaidya was an employee of Novartis Institutes for BioMedical Research, Inc., Cambridge, MA during the conduct of the study.

The authors received no compensation related to the development of the manuscript. Hanns-Christian (HCT) is an employee of and holds shares of Novartis Pharma AG. Brian Ethell (BE) is an employee of and holds shares of Novartis Pharma AG. Juergen Jauernig (JJ) is an employee and shareholder of Novartis Pharma AG. Dr. Soniya Vaidya (SV) is an employee of Axcella Health, Inc. and shareholder of Novartis Pharma AG.

Dr. S. David Miller does not report any conflict of interest (DV). The authors reported no conflict of interest relevant to the work presented here.

\section{Author details}

${ }^{1}$ Northeast Medical Research Associates Inc., North Dartmouth, MA, USA.

${ }^{2}$ Axcella Health, Cambridge, MA, USA. ${ }^{3}$ Novartis Pharma AG, Basel, Switzerland. ${ }^{4}$ Novartis Institutes for Biomedical Research, Cambridge, MA, USA. ${ }^{5}$ Novartis Healthcare Pvt. Ltd., Hyderabad, India. ${ }^{6}$ Novartis Institutes for Biomedical Research, Basel, Switzerland.

Received: 16 April 2020 Accepted: 6 September 2020

Published online: 23 September 2020

\section{References}

1. Global strategy for asthma management and prevention, Global Initiative for Asthma (GINA) 2019. Available from: http://www.ginasthma.org/. Accessed 16 Dec 2019.

2. Soriano JB, Abajobir AA, Abate KH, Abera SF, Agrawal A, Ahmed MB, et al. Global, regional, and national deaths, prevalence, disability-adjusted life years, and years lived with disability for chronic obstructive pulmonary disease and asthma, 1990-2015: a systematic analysis for the Global Burden of Disease Study 2015. Lancet Respir Med. 2017:5(9):691-706.

3. European Medical Agency. Available from: https://www.ema.europa.eu/en/ medicines/human/EPAR/onbrez-breezhaler. Accessed 8 Aug 2020.

4. Frampton JE. QVA149 (indacaterol/glycopyrronium fixed-dose combination): a review of its use in patients with chronic obstructive pulmonary disease. Drugs. 2014;74(4):465-88. 
5. Horita N, Kaneko T. Role of combined indacaterol and glycopyrronium bromide (QVA149) for the treatment of COPD in Japan. Int J Chron Obstruct Pulmon Dis. 2015;10:813.

6. Metaxas El, Balis E. The safety of indacaterol for the treatment of COPD. Expert Opin Drug Saf. 2018;17(6):637-42.

7. Dahl R, Chung KF, Buhl R, Magnussen $H$, Nonikov V, Jack D, et al. Efficacy of a new once-daily long-acting inhaled $\beta 2$-agonist indacaterol versus twicedaily formoterol in COPD. Thorax. 2010;65(6):473-9.

8. Feldman G, Siler T, Prasad N, Jack D, Piggott S, Owen R, et al. Efficacy and safety of indacaterol $150 \mu \mathrm{g}$ once-daily in COPD: a double-blind, randomised, 12-week study. BMC Pulm Med. 2010;10(1):11.

9. Juvelekian G, El-Sorougi W, Pothirat C, Yunus F, De Guia T, Kuo H-P, et al. A real-world evaluation of indacaterol and other bronchodilators in COPD: the INFLOW study. Int J Chron Obstruct Pulmon Dis. 2015;10:2109.

10. Cazzola M, Rogliani P, Matera MG. Ultra-LABAs for the treatment of asthma. Respir Med. 2019;156:47-52.

11. Chuchalin AG, Tsoi AN, Richter K, Krug N, Dahl R, Luursema P, et al. Safety and tolerability of indacaterol in asthma: a randomized, placebo-controlled 28-day study. Respir Med. 2007;101(10):2065-75.

12. Beasley RW, Donohue JF, Mehta R, Nelson HS, Clay M, Moton A, et al. Effect of once-daily indacaterol maleate/mometasone furoate on exacerbation risk in adolescent and adult asthma: a double-blind randomised controlled trial. BMJ Open. 2015:5(2):e006131.

13. Kanniess F, Boulet L-P, Pierzchala W, Cameron R, Owen R, Higgins M. Efficacy and safety of indacaterol, a new 24-hour $\beta$ 2-agonist, in patients with asthma: a dose-ranging study. J Asthma. 2008;45(10):887-92.

14. Beier J, Chanez P, Martinot J-B, Schreurs AJM, Tkácová R, Bao W, et al. Safety, tolerability and efficacy of indacaterol, a novel once-daily beta(2)-agonist, in patients with COPD: a 28-day randomised, placebo controlled clinical trial. Pulm Pharmacol Ther. 2007;20(6):740-9.

15. Yang WH, Martinot JB, Pohunek P, Beier J, Magula D, Cameron R, et al. Tolerability of indacaterol, a novel once-daily beta2-agonist, in patients with asthma: a randomized, placebo-controlled, 28-day safety study. Ann Allergy Asthma Immunol. 2007:99(6):555-61.

16. EU SMPC 2 European Medicines Agency (EMA): Indacaterol (Onbrez ${ }^{\circledR}$ ) full prescribing information (EU) Available from: Available from: https://ec europa.eu/health/documents/community-register/2009/2009113069149/ anx 69149 en.pdf. Accessed 4 Aug 2020.

17. Kornmann O, Mucsi J, Kolosa N, Bandelli L, Sen B, Satlin LC, et al. Efficacy and safety of inhaled once-daily low-dose indacaterol acetate/mometasone furoate in patients with inadequately controlled asthma: phase III randomised QUARTZ study findings. Respir Med. 2019;161:105809.

18. Jauernig JVS, Tillmann H, Ethell B, Kuttler A, Dimke T. Use of biophysical modeling to develop indacaterol / glycopyrronium / mometasone furoate inhaled combination: results from a salt-bridging study of indacaterol in patients with asthma. RDD Europe 2019. 2019;2:351-4.

19. Shimada S, Vaidya S, Khindri S, Tashiro N, Cheng Y, Hara H, et al. Pharmacokinetics of QMF149 in Japanese versus Caucasian subjects: an openlabel, randomized phase I study. Int J Clin Pharmacol Ther. 2015:53(5):398-407.

20. Guideline on the investigation of bioequvivalence 2010. Available from: https://www.ema.europa.eu/en/documents/scientific-guideline/guidelineinvestigation-bioequivalence-rev1_en.pdf. Accessed 29 July 2020.

21. Kornmann O, Dahl R, Centanni S, Dogra A, Owen R, Lassen C, et al. Oncedaily indacaterol versus twice-daily salmeterol for COPD: a placebocontrolled comparison. Eur Respir J. 2011:37(2):273-9.

22. Wolfe J, LaForce C, Friedman B, Sokol W, Till D, Della Cioppa G, et al. Formoterol, $24 \mu \mathrm{g}$ bid, and serious asthma exacerbations: similar rates compared with formoterol, $12 \mu \mathrm{g}$ bid, with and without extra doses taken on demand, and placebo. Chest. 2006;129(1):27-38.

23. Tepper RS, Wise RS, Covar R, Irvin CG, Kercsmar CM, Kraft M, et al. Asthma outcomes: pulmonary physiology. J Allergy Clin Immunol. 2012;129(3):S65-87.

24. Seth HD, Sultan S, Gotfried MH. Role of indacaterol, a once-daily bronchodilator, in chronic obstructive pulmonary disease. J Thorac Dis. 2013;5(6):806-14.

25. Donohue JF, Fogarty C, Lötvall J, Mahler DA, Worth H, Yorgancioglu A, et al. Once-daily bronchodilators for chronic obstructive pulmonary disease: indacaterol versus tiotropium. Am J Respir Crit Care Med. 2010;182(2):155-62.

26. Jiang J, Li L, Yin H, Woessner R, Emotte C, Li R, et al. Single-and multipledose pharmacokinetics of inhaled indacaterol in healthy Chinese volunteers. Eur J Drug Metab Pharmacokinet. 2015;40(2):203-8.
27. Vaidya SS, Khindri S, Calder N, Machineni S, Hara H, Majumdar T, et al. Pharmacokinetics of indacaterol and mometasone furoate delivered alone or in a free or fixed dose combination in healthy subjects. Pulm Pharmacol Ther. 2016:37:30-6.

28. Chen W, Johnson KM, FitzGerald JM, Sadatsafavi M, Leslie WD. Long-term effects of inhaled corticosteroids on bone mineral density in older women with asthma or COPD: a registry-based cohort study. Arch Osteoporos. 2018;13(1):116

29. Daugherty J, Lin X, Baxter R, Suruki R, Bradford E. The impact of long-term systemic glucocorticoid use in severe asthma: a UK retrospective cohort analysis. J Asthma. 2018;55(6):651-8.

30. Rice JB, White AG, Scarpati LM, Wan G, Nelson WW. Long-term systemic corticosteroid exposure: a systematic literature review. Clin Ther. 2017;39(11): 2216-29.

31. Yang WH, Martinot JB, Pohunek P, Beier J, Magula D, Cameron R, et al. Tolerability of indacaterol, a novel once-daily $\beta 2$-agonist, in patients with asthma: a randomized, placebo-controlled, 28-day safety study. Ann Allergy Asthma Immunol. 2007;99(6):555-61.

32. Bleecker ER, Siler T, Owen R, Kramer B. Bronchodilator efficacy and safety of indacaterol $150 \mu \mathrm{g}$ once daily in patients with COPD: an analysis of pooled data. Int J Chron Obstruct Pulmon Dis. 2011;6:431.

33. Chapman KR, Rennard SI, Dogra A, Owen R, Lassen C, Kramer B, et al. Longterm safety and efficacy of indacaterol, a long-acting 32 -agonist, in subjects with COPD: a randomized, placebo-controlled study. Chest. 2011;140(1):68-75.

34. Beier J, Chanez P, Martinot J-B, Schreurs A, Tkáčová R, Bao W, et al. Safety, tolerability and efficacy of indacaterol, a novel once-daily $\beta 2$-agonist, in patients with COPD: a 28-day randomised, placebo controlled clinical trial. Pulm Pharmacol Ther. 2007;20(6):740-9.

35. Rennard SI, Chapman KR, Luthra A, Swales J, Lassen C, Owen R, et al. Once-daily indacaterol provides effective bronchodilation over 1 year of treatment in patients with chronic obstructive pulmonary disease (COPD). Chest. 2009;136(4):4S.

\section{Publisher's Note}

Springer Nature remains neutral with regard to jurisdictional claims in published maps and institutional affiliations.

Ready to submit your research? Choose BMC and benefit from:

- fast, convenient online submission

- thorough peer review by experienced researchers in your field

- rapid publication on acceptance

- support for research data, including large and complex data types

- gold Open Access which fosters wider collaboration and increased citations

- maximum visibility for your research: over $100 \mathrm{M}$ website views per year

At $\mathrm{BMC}$, research is always in progress.

Learn more biomedcentral.com/submission 